\section{Reply to: Managing the high: developing legislation and detection methods for cannabis impairment}

\author{
Johannes G. Ramaekers (D), Natasha L. Mason (D), Lilian Kloft(D) and \\ Eef $L$. Theunissen (D)
}

We thank Thomas R. Arkell, Amie C. Hayley and Luke A. Downey for their comments on our recent Review (Ramaekers, J. G., Mason, N. L., Kloft, L. \& Theunissen, E. L. The why behind the high: determinants of neurocognition during acute cannabis exposure. Nat. Rev. Neurosci. 22, 439-454 $(2021))^{1}$ and their contribution to discussions of the implications of this growing field of research (Arkell, T. R., Hayley, A. C. \& Downey, L. A. Managing the high: developing legislation and detection methods for cannabis impairment. Nat. Rev. Neurosci. https://doi.org/10.1038/s41583-021-00500-5 $(2021))^{2}$

In line with others ${ }^{3-5}$, Arkell et al. suggest that uniform standards around $\Delta^{9}$-tetrahydrocannabinol (THC) dosing might increase comparability between scientific studies and support informed decision making among consumers. We have previously argued $^{6,7}$ that the best way to increase comparability between THC studies on neurocognitive function is to report both THC dose (in mass; mg) and blood THC concentration. The main reason for this suggestion is that comparison between absolute or standard units of THC doses can be misleading because of variations in administration procedures employed across studies. Variations in puff volume, number of puffs and breath-hold duration while smoking cannabis produce dose-related changes in plasma levels of $\mathrm{THC}^{8}$. Likewise, different routes of administration (such as smoking, vaporization and orally ingestion) produce marked differences in bioavailability and the overall pharmacokinetic and neurocognitive profile of THC at any given dose $\mathrm{e}^{1,9}$. Moreover, our Review ${ }^{1}$ also highlights how the impact of THC on neurocognitive function can be impacted by a range of additional factors, such as the cannabinoid composition of the cannabis products and the individual's cannabis use history, that cannot be deduced from information on THC dose alone. From a consumer perspective, it might therefore be appropriate to provide estimates on the expected strength of the cannabis experience for separate cannabis product types or treatments, while taking into account a multitude of contributory factors such as THC dose, route of administration, cannabinoid composition and frequency of use.

We agree with Arkell and colleagues that systems that monitor driver state potentially provide an objective method to support the detection and indexing of driving impairment in naturalistic settings. Such systems might also contribute to the targeted detection of cannabis-induced impairment if it can be shown that alterations in physiological parameters, such as gaze monitoring or eyeclosure metrics, are selectively associated with acute cannabis exposure and not to the use of other drugs or non-drug related physical or neurological conditions. If selectivity cannot be shown, then indications of driver impairment provided by driver monitoring systems might only be related to acute cannabis exposure if supplemental evidence on the presence of relevant THC levels in blood is available. Future detection of the impact of acute cannabis exposure on driver state might therefore benefit from combined assessment of driver state and THC levels in blood to relate driver-state-monitoring data to cannabis use and to avoid false positive findings that could arise from isolated detection and interpretation of THC in blood.

Johannes G. Ramaekers (iD ${ }^{凶}$, Natasha L. Mason (iD, Lilian Kloft iD and Eef L. Theunissen (D) Faculty of Psychology and Neuroscience, Maastricht University, Maastricht, The Netherlands.

凶e-mail: j.ramaekers@maastrichtuniversity.nl https://doi.org/10.1038/s41583-021-00501-4

1. Ramaekers, J. G., Mason, N. L., Kloft, L. \& Theunissen, E. L. The why behind the high: determinants of neurocognition during acute cannabis exposure. Nat. Rev. Neurosci. 22. 439-454 (2021).

2. Arkell, T. R., Hayley, A. C. \& Downey, L. A. Managing the high: developing legislation and detection methods for cannabis impairment. Nat. Rev. Neurosci. https:// doi.org/10.1038/s41583-021-00500-5 (2021).

3. Casajuana, C. et al. Working on a Standard Joint Unit: A pilot test. Adicciones 29, 227-232 (2017).

4. Freeman, T. P. \& Lorenzetti, V. 'Standard THC units' a proposal to standardize dose across all cannabis products and methods of administration. Addiction 115, 1207-1216 (2020).

5. Volkow, N. D. \& Weiss, S. R. B. Importance of a standard unit dose for cannabis research. Addiction 115, 1219-1221 (2020).

6. Ramaekers, J. G., Kauert, G. F., Theunissen, E. L. \& Moeller, M. R. Up in Smoke: comparability of THC dosing across performance studies. Neuropsychopharmacology 31, 2800-2801 (2006).

7. Ramaekers, J. G., Mason, N. L. \& Theunissen, E. L. Blunted highs: pharmacodynamic and behavioral models of cannabis tolerance. Eur. Neuropsychopharmacol. 36, 191-205 (2020).

8. Azorlosa, J. L., Greenwald, M. K. \& Stitzer, M. L. Marijuana smoking: effects of varying puff volume and breathhold duration. J. Pharmacol. Exp. Ther. 272, 560-569 (1995).

9. McGilveray, I. J. Pharmacokinetics of cannabinoids Pain Res. Manag. 10, 15A-22A (2005).

Competing interests

The authors declare no competing interests. 